\title{
CURRENT FLOW DYNAMICS IN PLASMA OPENING SWITCH
}

\author{
O.V. Manuilenko, I.N. Onishchenko, A.V. Pashchenko, I.A. Pashchenko, V.B. Yuferov \\ National Science Center “Kharkov Institute of Physics and Technology”, Kharkiv, Ukraine \\ E-mail: paschenko@kipt.kharkov.ua
}

The electromagnetic fields and processes of current flow in the plasma channel of the plasma opening switch were considered in the electron hydrodynamics approximation. Taking into account the nature and features of the current flow through the plasma filled region of plasma opening switch allowed to obtain the structure of the current channel and its dynamics along the plasma. The current flow is a wave process. When this wave reaches the boundary of plasma it seems to be the break of current at this moment. The criterion of this break is obtained.

PACS: 52.75.- d, 94.20.wc

\section{INTRODUCTION}

Plasma opening switch (POS) is a plasma device that provides the current interruption in a time small compared to the characteristic time of electrical circuit. This time can range from nanoseconds to microseconds, depending on the parameters of the installation. High power currents can interrupt by such switches at high voltages. POS is used to filter pre-pulses, sharpen the diode power, increase the energy characteristics of relativistic electron beams, and so on. Despite decades of using POS, their experimental and theoretical studies [17], the essence of the processes in them remains not enough clear.

The physical processes in the plasma of POS are the subject of this theoretical study. POS for nanosecond high voltage pulses typically is coaxial inductive energy storage (IES) with plasma and microsecond current pulse passes through this plasma region. The process is organized according to the criterion that at the moment of maximum current its circuit is opened and a high voltage pulse appears at the plasma boundary.

The set of experimental results and theoretical estimates shows that the plasma channel in the IES has a resistance of $Z_{p} \approx 0.01 \Omega$. This means that voltage on the plasma channel $\left(I \cdot Z_{p}\right)$ can be only about $1 \mathrm{kV}$ even at the maximum current $\left(I_{\max } \approx 100 \mathrm{kA}\right)$ in the primary circuit. Thus, the plasma of the POS together with the electrodes of IES is a coaxial plasma diode, through which a huge current is passed at a relatively low voltage (less than $1 \mathrm{kV}$ ) on it. So, POS is a current device in which the main electrodynamic processes are related to the current. Such a peculiarity is taken into account in our study. Taking into account the nature and features of the current flow through the plasma filled region of POS allowed to obtain the structure of the current channel (distribution of current density and electromagnetic fields) and its dynamics along the plasma.

\section{MODEL DESCRIPTION}

The expression for the current density passing through such a diode can be found from the equations of electron hydrodynamics

$$
\frac{\partial \vec{v}}{\partial t}+(\vec{v} \nabla) \vec{v}+v_{e i} \vec{v}=-\frac{e}{m}[\vec{E}+[\vec{v} \vec{B}]]
$$

$$
\begin{aligned}
& \frac{\partial n}{\partial t}+\operatorname{div}(n \vec{v})=0, \\
& \operatorname{rot} \vec{E}=-\frac{\partial \vec{B}}{\partial t}, \\
& \operatorname{rot} \vec{H}=\frac{\partial \vec{D}}{\partial t}+\vec{j}, \\
& \operatorname{div} \vec{D}=\rho_{i}-\rho_{e} .
\end{aligned}
$$

In equations (1)-(5) the traditional notations are used.

First of all equation (1) is considered. In (1) the frequency of electronic collisions is [8]:

$$
v_{e}=\frac{n}{3.5 \cdot 10^{10} \cdot T_{e}^{3 / 2}},
$$

where $T_{e}$ is the temperature of the electrons $(\mathrm{eV})$. For the frequency of electronic collisions we have $v_{\mathrm{e}}>10^{7} \mathrm{~s}^{-1}$ at $T_{e} \approx 4 \ldots 7 \mathrm{eV}$ and $\mathrm{n}>10^{19} \mathrm{~m}^{-3}$.

The terms with derivatives in equation (1) are proportional to the frequency of current oscillations $(f=1 / T)$ in the primary circuit of the POS with period $T \approx 6 \mathrm{mks}$. This means that they are much smaller than others, so the components with derivatives in equation (1) can be neglected and it takes the form:

$$
v_{e i} \vec{v}=-\frac{e}{m}[\vec{E}+[\vec{v} \vec{B}]],
$$

where $E_{r^{-}}, E_{z^{-}}, H_{\phi^{-}}$-components of the electromagnetic field, generally speaking, can occur in the plasma channel. However, based on the large length of the coaxial electrodes, further it is assumed that the plasma has only $E_{r}$-component of the electric field. Then, from equation (1a), expressions for $v_{r}$ and $v_{z}$ can be obtained:

$$
\begin{aligned}
& v_{r}=\frac{\frac{e}{m} v_{e}}{v_{e}^{2}+\omega_{H}^{2}} E_{r}, \\
& v_{z}=\frac{\frac{e}{m} \omega_{H}}{v_{e}^{2}+\omega_{H}^{2}} E_{r},
\end{aligned}
$$

where

$$
\omega_{H}=\frac{e \mu_{0} H_{\varphi}}{m},
$$

and $\mu_{0}=4 \pi \cdot 10^{-7} \mathrm{Hn} / \mathrm{m}$. 
Ohm's law for the current density through the plasma can be obtained by multiplying equations (7) and (8) by the product $(e n)$ :

$$
\begin{aligned}
& j_{r}=\frac{\sigma_{0}}{1+\left(\frac{\omega_{H}}{v_{e}}\right)^{2}} E_{r}, \\
& j_{z}=\frac{\sigma_{0} \frac{\omega_{H}}{v_{e}}}{1+\left(\frac{\omega_{H}}{v_{e}}\right)^{2}} E_{r},
\end{aligned}
$$

where

$$
\begin{gathered}
\sigma_{0}=\frac{\omega_{0}^{2} \varepsilon_{0}}{v_{e}}, \\
\omega_{0}^{2}=\frac{e^{2} n}{m \varepsilon_{0}} .
\end{gathered}
$$

Substitution of (6) and (11) in (10) leads to the following result:

$$
\sigma_{0} \approx 10^{3} T_{e}^{3 / 2}
$$

where $\left[T_{e}\right]=e V,\left[\sigma_{0}\right]=\frac{F}{m \cdot s}$. Conductivity $\sigma_{0}$ is proportional $T_{e}^{3 / 2}$, as the electrons deceleration due to collisions decreases with the increase of their temperature.

According to (7a) the current density is determined by the plasma conductivity $\sigma_{0}$ when the current values provide the conditions $\left(\omega_{H} / v_{e}\right)^{2} \leq 1$. When $\omega_{H} / v_{e}>1$ plasma conductivity decreases due to plasma magnetization. According to estimations the plasma density $n \approx 2 \cdot 10^{23} \mathrm{~m}^{-3}$ provides its conductivity through the electronic channel up to the current $\mathrm{I} \approx 10^{5} \mathrm{~A}$. At plasma densities $n \approx 10^{20} \ldots 10^{22} \mathrm{~m}^{-3}$ the current transport without magnetic field restrictions is possible only up to values of $0.1 \ldots 10 \mathrm{kA}$.

Next we will proceed from the nature and features of the current flow through the plasma of the POS. After operation of the gas discharger the primary circuit is closed through plasma by current channels located at different distances along axis $z$. The current channels closer to the capacitor bank form circuits with lower inductance and, accordingly, lower inductive resistance. Therefore, the main current channel will occur in the plasma at the boundary $(z=0)$ closest to the capacitor bank. This self-consistent process is considered based on equation (7a). Let's write it in the form:

$$
\bar{j}_{r}(z)=\frac{a}{1+b\left(1-\int_{0}^{z} \bar{j}_{r} d z\right)^{2}},
$$

where

$$
a=\sigma_{0} E_{r} \frac{2 \pi r_{1} l}{I(t)}, b=\frac{e \mu_{0}}{m v_{e} 2 \pi r_{1}}(I(t))^{2}, \bar{j}_{r}=j_{r} \frac{2 \pi r_{1} l}{I(t)},
$$

$l$ - the length of plasma along $z$-axis. Hereinafter, the current density is considered at the boundary of the central electrode, where the current is divided into components - the current through the plasma and the current along the central electrode. The integral of the dimensionless current density corresponds to the part of the current that flow into the plasma starting from its boundary close to the capacitor bank $(z=0)$ and up to the $z$-coordinate. At this point the magnetic field is created by the current that reaches it along the central electrode, i.e. the difference between the total current and the current that flows into the plasma on the distance from its beginning $(z=0)$ to point $z$. We have formula (9) for $\omega_{H}$ in which the magnetic field is taken in the form $H_{\varphi}=I(t) /\left(2 \pi r_{1}\right)$, where $I(t)$ is the total current of the primary circuit of the POS, $r_{1}$ - the radius of the central electrode of the IES.

\section{STRUCTURE OF THE CURRENT FLOW}

One can obtain using (6) and (9):

$$
\frac{\omega_{H}}{v_{e}} \approx 5 \cdot 10^{17} \frac{I}{n} \text {. }
$$

The following differential equation can be written from (12) after change $\bar{j}_{r}=\frac{d w}{d \zeta}$, where $\zeta=z / l$

$$
\frac{d w}{d \zeta}=\frac{a}{1+b[1-w]^{2}} .
$$

The explicit form of $a$ is found by the solution of equations (1)-(5) for $E_{r}$. This gives an opportunity to obtain profile of current channel and its movement along the $z$-axis. At this stage the estimation $E_{r}=I(t) \cdot Z_{p} /\left(r_{2}-r_{1}\right)$ will be applied.

The solution of equation (14) under the boundary condition $\left.w\right|_{\zeta=0}=0$ is

$$
w-\frac{b}{3}(1-w)^{3}=a \zeta-\frac{b}{3},
$$

$w$ is the total current if $\zeta=\zeta^{\prime}=z^{\prime} / l$, i.e. $\left.w\right|_{\zeta=\zeta^{\prime}}=1$.

The condition for the total current through the plasma is obtained from (15):

$$
1=a \zeta^{\prime}-\frac{b}{3} \text {. }
$$

The largest current that can be flowed through the POS' plasma is obtained in the case when the current flow extends to the entire length of the plasma, i.e. when $\zeta^{\prime}=1$. The condition for the maximum current $I_{\max }$ that can be transmitted by the POS' plasma, can be received from (16) given the values of $a$ and $b$ :

$$
\begin{aligned}
I_{\max } & =\frac{2 \pi m_{e} n}{e \mu_{0} 3.5 \cdot 10^{10} T_{e}^{3 / 2}} \sqrt{\frac{6 \pi r_{1} \sigma_{0} l Z_{p}}{r_{2}-r_{1}}-3} \approx \\
& \approx 1.4 \cdot 10^{-15} \frac{n}{T_{e}^{3 / 2}} \sqrt{5 \cdot 10^{4} \frac{r_{1} l Z_{p}}{r_{2}-r_{1}}-1 .}
\end{aligned}
$$

Dependence (17) is shown in Figs. 1 and 2 under the parameters that represent usual experimental conditions. 


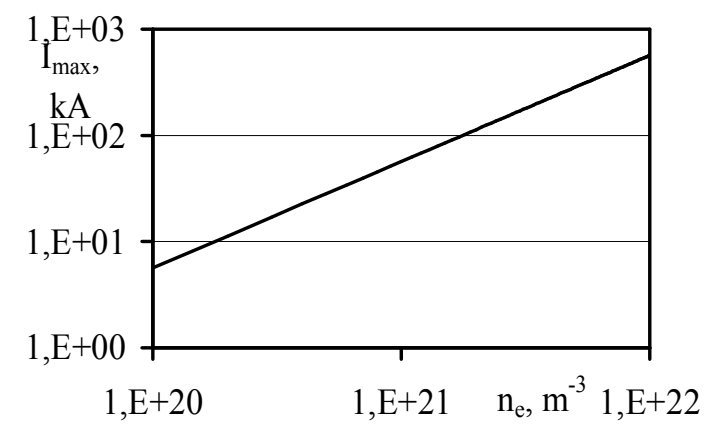

Fig. 1. The dependence of the maximum current that can transmit by $P O S^{\prime}$ plasma on the plasma density. $T_{e}=4 \mathrm{eV}, Z_{p}=0.01 \Omega, r_{1}=0.04 \mathrm{~m}$ and $r_{2}=0.1 \mathrm{~m}$,

$$
l=0.2 \mathrm{~m}
$$

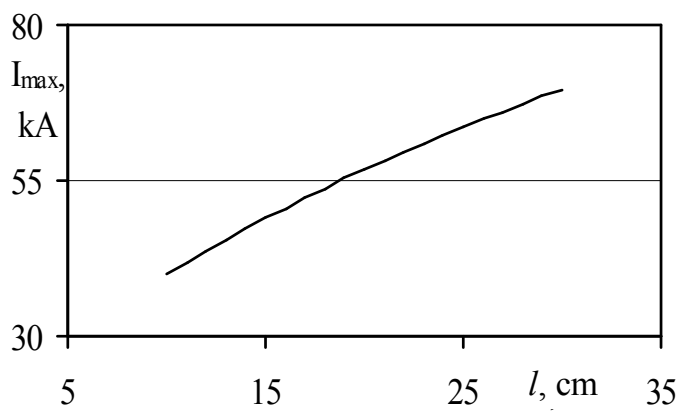

Fig. 2. The dependence of the maximum current that can transmit by POS' plasma on the plasma length. $T_{e}=4 e V, Z_{p}=0.01 \Omega, r_{1}=0.04 \mathrm{~m}$, and $r_{2}=0.1 \mathrm{~m}$,

$$
n=10^{21} \mathrm{~m}^{-3}
$$

Equation (12) gives the distribution of the radial current density $j_{r}(z)$ along the plasma. The dynamics of the current channel is demonstrated by current density distribution for four serial time points in Fig. 3 The dependence of the current of the POS' primary circuit, which flows through the plasma, was taken in the form $I(t)=I_{\max } \sin \left(\frac{2 \pi}{T} t\right)$ to calculate the $j_{r}(z)$.

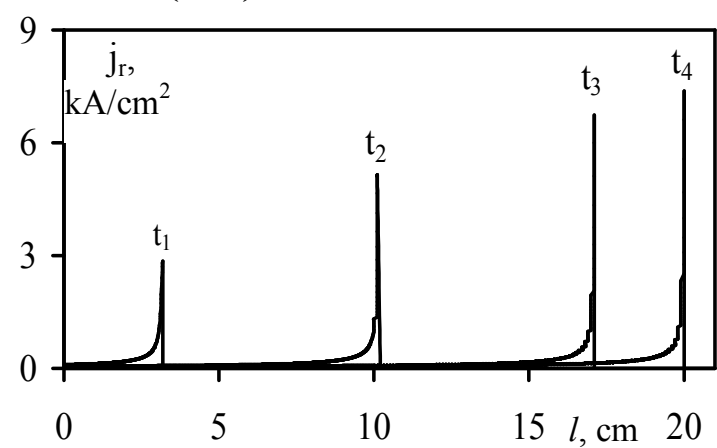

Fig. 3. Distribution of radial current density along the plasma and the dynamics of the current channel with POS' total current increase:

$$
\begin{gathered}
t_{1}=T / 16=0.375 \mu s\left(I_{1}=21.7 \mathrm{kA}\right), \\
t_{2}=T / 8=0.75 \mu s\left(I_{2}=40.1 \mathrm{kA}\right), \\
t_{3}=3 T / 16=1.125 \mu \mathrm{s}\left(I_{3}=52.4 \mathrm{kA}\right), \\
t_{4}=T / 4=1.5 \mu \mathrm{s}\left(I_{4}=56.7 \mathrm{kA}\right) .
\end{gathered}
$$

The calculations that were made within the assumptions discussed above and are presented in Fig. 3 allow us to conclude that the current channel occupies only part of the plasma. The boundary of the current flow, far from the capacitor bank, moves along $z$-axis with increasing of total current in the POS' primary circuit. Thus, the current flow through the plasma is a kind of wave process, which is cased by the redistribution of the magnetic field and the change in the magnetization of the plasma. Indeed, the electrons in the current channel at the boundary of the plasma close to the capacitor bank $(z=0)$ are magnetized with current increase. This leads to a decrease of the current density in accordance with the magnetic field. The magnetic field decreases from the maximum at the boundary of the current channel close to the capacitor bank $(z=0)$ to zero at the far one $\left(z=z^{\prime}\right)$.

Accordingly, the current density (12) will increase from the minimum value at the close boundary, reach a maximum at the far boundary of the flow and fall sharply to zero on it. The integral of the current density within these limits will be equal to one $\int_{0}^{z^{\prime}} \bar{j}_{r} d z=1$. The magnetization limitation of the current channel causes it to expand in the direction of the far boundary of the plasma. The current density at the beginning of the flow $(z=0)$ decreases and at the end $\left(z=z^{\prime}\right)$ increases. In general, the process under consideration is the propagation of a current density wave with velocity

$$
v_{z^{\prime}}=\frac{d z^{\prime}}{d t}=10^{4} \frac{l}{v_{e}^{2} r_{1}^{2}} \frac{d}{d t}\left(I^{2}\right)[\mathrm{m} / \mathrm{s}] .
$$

\section{DYNAMICS OF EM-FIELDS}

In this study the possibility of the wave nature of the current flow was analyzed based on the equations of electron hydrodynamics (1)-(5).

Equations for electromagnetic fields occuring in POS' plasma during electron current flow were solved together with expressions (7), (8) for electron velocities and expressions (7a), (8a) for electron current density. From equations (3), (4) one can obtain for $E_{r}$ and $H_{\varphi}$ :

$$
\begin{gathered}
-\frac{\partial H_{\varphi}}{\partial z}=\varepsilon \frac{\partial E_{r}}{\partial t}+j_{r}, \\
\frac{1}{r} \frac{\partial}{\partial r}\left(r H_{\varphi}\right)=j_{z}, \\
\frac{\partial E_{r}}{\partial z}=-\mu \frac{\partial H_{\varphi}}{\partial t} .
\end{gathered}
$$

Whence, the equation for $H_{\varphi}$ is received taking into account (7a), (8a) for $j_{r}$ and $j_{z}$, after excluding the ratio $E_{r} /\left(v_{e}^{2}+\omega_{H}^{2}\right)$, the differentiation of the result by $z$ and the substitution of the derivative $\partial E_{r} / \partial z$ from (14):

$$
\frac{\partial^{2} \Omega}{\partial \tau^{2}}=\frac{\partial^{2} \Omega}{\partial \zeta^{2}}+\left(\frac{l}{r_{2}}\right) \frac{\partial^{2}}{\partial \zeta \partial \rho}[\ln (\rho \Omega)]
$$


where $\Omega=\omega_{H} / v_{e}, \quad \zeta=z / l, \quad \rho=r / r_{2}, \quad \tau=\bar{c} t / l$, $\bar{c}=c / \sqrt{\varepsilon \mu}, c=1 / \sqrt{\varepsilon_{0} \mu_{0}}$.

The method of variables separation can be used to rewrite equations (20), (21):

$$
\begin{gathered}
H_{\varphi}(\rho, \zeta, \tau)=H_{1}(\zeta, \tau) H_{2}(\rho), \\
E_{r}(\rho, \zeta, \tau)=E_{1}(\zeta, \tau) E_{2}(\rho),
\end{gathered}
$$

that gives

$$
E_{2}(\rho)=\frac{1}{D} H_{2}(\rho)=\frac{1}{\rho D\left(1+\ln \frac{\rho}{\rho_{1}}\right)}
$$

and wave equation for $H_{1}(\zeta, \tau)$

$$
\frac{\partial^{2} H_{1}}{\partial \tau^{2}}=\frac{\partial^{2} H_{1}}{\partial \zeta^{2}}
$$

where $D$ is the constant of separation.

The general solution of equation (24) in the class of trigonometric functions can be obtained by the method of separation of variables. Then, based on this solution, the description of the motion of any initial and boundary profile along the $z$-axis can be received according to the well known procedure. This is wave propagation. Functions describing a wave moving in the positive direction of the $z$-axis depend on the argument $(\zeta-\tau)$, i.e.

$$
H_{1}(\zeta, \tau)=f(\zeta-\tau) \text {. }
$$

Equation (20) with dimensionless arguments $\zeta$ and $\tau$ is taken the form:

$$
\frac{\partial E_{r}}{\partial \zeta}=-\chi \frac{\partial H_{\varphi}}{\partial \tau}
$$

were $\chi=c \sqrt{\frac{\mu}{\varepsilon}}$. By substituting expressions (22), (23), (25) in (20a) one can obtain $E_{1}(\zeta, \tau)=\chi D H_{1}(\zeta, \tau)$ and, as a result,

$$
E_{r}=\chi H_{\varphi} .
$$

The preliminary approximation (14) gave us a wave of current density, in front of which no current flowed. The magnetic field in such a wave goes down to zero at the front of this wave $\left(z=z^{\prime}\right)$ together with the current flowing along the central electrode. Indeed, as it follows from equation (26) the electric field in the radial direction is also zeroed at zero magnetic field. The absence of an electric field in front of the wave is agreed with the absence of current in this part of the POS' plasma.

In this consideration the zero electric field is obtained for the plasma in front of the current wave (current loop) in the presence of electric potential at the electrodes. There is no contradiction in this, because the near-electrode layers of space charge were not taken into account, but namely on them all the electric potential applied to the interelectrode gap can drop. It was sufficient for this analysis to obtain solutions only for the plasma region.

\section{CONCLUSIONS}

The executed research allows us to conclude that the current flow through the POS' plasma occurs as the propagation of wave structure through it. This structure formed by the current density $j_{r}$ and self-consistent fields $E_{r}$ and $H_{\varphi}$. We consider that the current interruption can be realized in IES with POS and cause overvoltage between electrodes when the wave reaches the far boundary $(z=l)$ of the plasma and some electrons are ejected from it. It is assumed that strong disturbance of the wave structure is made at this moment. This disturbance triggers a mechanism of instability, which leads to a sharp decrease of radial current.

The distribution of the dimensionless radial current density along the plasma, calculated from equation (12), is shown in Fig. 4 for the moment when the current channel expands to the boundaries of POS' plasma $\left(z^{\prime}=l\right)$. Also there is a dependence of the current that passed through the plasma from its beginning at $z=0$ to the point $z\left(\int_{0}^{z} j_{r} d z\right)$. It can be noted that a significant part of the current flows in the magnetized region of the plasma behind the wave structure, where the current density is in orders of magnitude less than at the wave front. In most experiments, there is a decrease in current by approximately $30 \%$ when the current interruption occurs. It can be assumed according to Fig. 4 that the instability caused by the wave reaching the boundary of the plasma $\left(z^{\prime}=l\right)$, leads to the destruction of the wave structure and the loss of the current related to it.

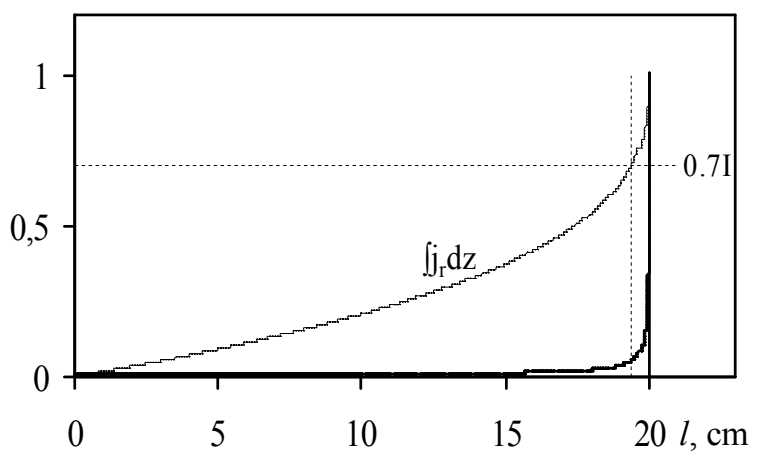

Fig. 4. Distribution of the radial current density along the plasma and the current that flow through it from its

$$
\begin{gathered}
\text { beginning }(z=0) \text { to the point } z, n=10^{21} \mathrm{~m}^{-3}, \\
T_{e}=4 \mathrm{eV}, Z_{p}=0.01 \Omega, r_{1}=0.04 \mathrm{~m}, r_{2}=0.1 \mathrm{~m}, \\
z^{\prime}=l=0.2 \mathrm{~m}, T=6 \mu \mathrm{s}
\end{gathered}
$$

Thus, the model of physical processes can be represented as follows: the current flow in the electric circuit of the POS is accompanied by the propagation of wave of current density and fields along the plasma; current interruption occurs when the wave reaches the boundary of the plasma. So, two scenarios of POS functioning can consider: (1) current interruption occurs at the front of the total current pulse in the case when the parameters of the primary electrical circuit of the POS and the amount of energy stored in the capacitor bank can provide the amplitude of current fluctuations $I_{a}$ $\left(I=I_{a} \sin \left(\frac{2 \pi}{T} t\right)\right)$ in circuit greater than the maximum current $I_{\max }$ that can flow through the plasma $I_{a} \geq I_{\max }$; (2) current interruption does not occur when 
the wave does not reach the boundary of the plasma, i.e. when the maximum current amplitude $I_{a}$ does not exceed the current $I_{\max }$ that can flow through the plasma.

A set of parameters can be considered optimal when it ensures the equality of the maximum possible current $I_{a}$ of the electric circuit of the POS and the maximum current $I_{\max }$ that can pass through the POS' plasma $I_{a}=I_{\max }$. Then the interruption will occur at the moment $(t=T / 4)$ when the maximum share of energy stored in the capacitor bank is converted into the energy of the magnetic field of the current.

The solutions of the problems for fields, current, and electron motion made it possible to formulate a set of processes in the POS' plasma from the moment of highvoltage gas discharger closure to the current interruption in the POS circuit. The current starts to flow at the boundary of the plasma $(z=0)$ close to the capacitor bank, and even at relatively small values ( 100 A) leads to magnetization of electrons in the current channel. As a result, the current channel expands along $z$-axis and takes a structure inhomogeneous in relation to current density. This is caused by the decrease of the magnetic field in the middle of the channel from the maximum value at the boundary close to the current source to zero at the far boundary $\left(z=z^{\prime}\right)$. Accordingly, the current density has a maximum value at the boundary with zero magnetic field. This wave structure propagates along the plasma with increasing of total current. When the wave reaches its far boundary $(z=l)$, the electrons of the current channel are partially ejected outside the plasma. This process causes instability, which destroys the waveform of the channel structure. In this case, the current loses the share that flows through the high current density region which directly borders to the boundary of the plasma.

\section{REFERENCES}

1. C.W. Mendel, S.A. Goldstein. A fast opening switch for use in REB diode // Journal of Applied Physics. 1977, v. 48, p. 1004.

2. R.A. Meger, R.J. Commisso, G. Cooperstein, S.A. Goldstein. Vacuum inductive store/pulse compression experiments on a high power accelerator using plasma opening switches // Applied Physics Letters. 1983, v. 42, p. 943.

3. P.F. Ottinger, S.A. Goldstein, R.A. Meger. Theoretical modeling of the plasma erosion opening switch for inductive storage applications // Journal of Applied Physics. 1984, v. 56, p. 774.

4. A.S. Kingsep, Yu.V. Mokhov, K.V. Chukbar // Fizika Plazmy. 1984, v. 10, p. 854.

5. G.I. Dolgachev, L.P. Zakatov, V.A. Skorupin // Fizika Plazmy. 1987, v. 13, p. 760.

6. G.I. Dolgachev, A.S. Kingsep, A.G. Ushakov. Dynamics of the current front in a current-carrying plasma bridge // Plasma Physics Reports. 2001, v. 27, p. 62.

7. G.I. Dolgachev, E.D. Kazakov, Yu.G. Kalinin, D.D. Maslennikov, A.A. Shvedov. RS-20MR HighCurrent Relativistic Electron Beam Generator Based on a Plasma Opening Switch and Its Applications // Plasma Physics Reports. 2019, v. p. 45, 315.

8. S.I. Braginskij. Problems of Plasma Theory. V. $1 /$ ed. M.A. Leontovich. Moscow: "Atomizdat", 1963.

Article received 17.06.2021

\section{ДИНАМИКА ПРОТЕКАНИЯ ТОКА В ПЛАЗМЕННОМ КОММУТАТОРЕ ТОКА}

\section{О.В. Мануйленко, И.Н. Онищенко, А.В. Пащенко, И.А. Пащенко, В.Б. Юферов}

Методами электронной гидродинамики были рассмотрены процессы переноса тока и электромагнитные поля в плазменной перемычке плазменного коммутатора тока. Учет характера и особенностей протекания тока по плазменной перемычке позволил получить структуру канала тока и его динамику вдоль нее. Протекание тока представляет собой волновой процесс. Размыкание тока связано с достижением этой волной границы плазменной перемычки. Получен критерий размыкания тока.

\section{ДИНАМІКА ПРОТІКАННЯ СТРУМУ В ПЛАЗМОВОМУ КОМУТАТОРІ СТРУМУ}

\section{О.В. Мануйленко, І.М. Оніщенко, А.В. Пащенко, І.А. Пащенко, В.Б. Юферов}

Методами електронної гідродинаміки були розглянуті процеси переносу струму та електромагнітні поля в плазмовій перемичці плазмового комутатора струму. Врахування характеру та особливостей протікання струму по плазмовій перемичці дозволило отримати структуру каналу струму та його динаміку вздовж неї. Протікання струму являє собою хвильовий процес. Розмикання струму пов'язане 3 досягненням цією хвилею границі плазмової перемички. Отримано критерій розмикання струму. 